\title{
May Science Be with You: Can Scientific Expertise Confer Legitimacy to Transnational Authority?
}

\author{
Vesco Paskalev
}

\begin{abstract}
The paper draws on the recent science and technology scholarship (STS) to criticise the dominant understanding of the role of science on which the existing system of transnational regulation is based. In particular, it employs the concept of epistemic subsidiarity suggested by Sheila Jasanoff to the science-based regulation in the EU to explain why the formal authority of the GMO regulators is crumbling, while some transnational regimes with no formal legal foundation flourish. It argues that to build their own authority, transnational regimes must not dismiss local concerns as 'unscientific' and 'political' but should themselves seek to take these concerns into account. The paper explores several ways in which this might be done in a multilevel system and concludes that instead of seeking to circumscribe the domains, we should strive to make their boundaries more porous.
\end{abstract}

\section{Key words}

expertise, authority, epistemic subsidiarity; risk regulation; co-production

About a dozen years ago, the EU sought to try whether the employment of best available science can confer legitimacy to a controversial transnational regulation, and it conducted what we may qualify as a natural experiment. The EU established a centralised system for regulation of genetically modified organisms (GMO) which is heavily reliant on science. By now we have sufficient evidence to conclude that the initial hypothesis has been proven wrong, at least for the conditions in which the EU employed science in this particular area. The established regime has failed to solve any of the problems it was

\footnotetext{
* Lecturer, University of Hull. The author wishes to thank to Andreas Glöckner, Bas Schotel, Nico Krisch, Christina Eckes, Joana Mendes, Machiko Kanetacke and all of the participants in the workshop Transnational Standards in the Domestic Legal Order: Authority and Legitimacy for the helpful questions. All mistakes or omissions are my own. I am especially grateful to Machiko for her comments on the earlier draft of this paper and for her patience and flexibility, without which this paper would not have been written.
} 
meant to, which the European Commission half-heartedly admits now, ${ }^{1}$ and proposes to allow to the disgruntled states to opt-out of it. This paper will take the lesson from the example of the EU's regulation of GMO further. The paper starts with a challenge of the conventional wisdom that scientific expertise is a way to justify authority. Section one discusses the relationship between authority and science on two levels where various organisations claim authority—national and transnational ${ }^{2}$ and the subversive interaction between science on one level and authority on another. The section concludes with the claim that the authority of the transnational regulatory regimes inevitably varies across the different domestic legal orders in which the regulations are applied. Section two uses the history of GMO regulation in the EU to illustrate how the reliance on scientific excellence failed to confer authority to the regulatory regime. Section three focuses on the subtle differences in the way science is employed in the build up of authority within nation states and argues that by ignoring these differences transnational regulation squanders its own claim to authority. The latter can be remedied, as the fourth section suggests, if transnational regimes themselves seek to account for and accommodate local concerns and the section explores several ways in which this might be achieved. The paper concludes with the claim that instead of trying to define the domains of science and politics respectively, we should seek to integrate them and use science to inform decision-making at every level and every stage.

\section{AUTHORITY AND SCIENCE}

\footnotetext{
${ }^{1}$ Communication from the Commission Reviewing the decision-making process on GMOs, COM (2015) 176 final from 22.4.2015. See author's analysis of Commission's review in European Journal of Risk Regulation, forthcoming in 2016.

2 I shall use 'transnational' as an umbrella term for any regime beyond the state, including supranational (e.g. EU) and international (e.g. WTO) as well as private regulators such as FSC and MSC.
} 
One of the features of authority is that its emergence is somewhat circular; authorities constitute themselves by virtue of the claims to authority they make. According to Joseph Raz, '[1]aw's claim to authority is manifested by the fact that legal institutions ... regard themselves as having the right to impose obligations on their subjects, by their claims that their subjects owe them allegiance' ${ }^{3}$ Conversely, for an institution, to exercise authority means that people generally accept its claim and treat it as having authority. Thus, authority is a social fact, just as the Hartean Rule of Recognition ${ }^{4}$ is a social fact. Certainly, not all institutions which claim authority succeed to be recognised as such; they have to work to substantiate their claims, and some claims will fall flat. ${ }^{5}$ On the other hand, even though the authority constitutes itself in such a circular manner, it always justifies its claims with something external, the trust in which can be taken for granted - be it divine revelation, tradition, or democratic election.

One such method for supporting the claims to authority, which is gaining increasing appeal in the last decades, is scientific or technical expertise. This is especially so for private or transnational organisations, for whom the other sources of support are generally unavailable, but also for the EU, which has certain democratic underpinning. Indeed, from the outset, the EU has been praised precisely as a system for entrusting certain matters to governance by experts. ${ }^{6}$ Hardly anyone would doubt at present that scientific expertise can and should be used to support authoritative decision-making and this paper does not contest this in any way. Yet science can be used (and produced) in many different ways, and there are different ways to define what counts as scientific. As will be argued below, the employment of science as a source of political authority is a

\footnotetext{
${ }^{3}$ Joseph Raz, 'Authority, Law, and Morality' (1985) 68 The Monist 295.

${ }^{4}$ H.L.A. Hart, The Concept of Law (Oxford University Press 2012).

${ }^{5}$ People may accept the claims to authority for various reasons - sense of moral obligation, fear, emotional bonds, etc. Unlike public trust, which is a measure of certain subjective attitudes of the relevant citizens or stakeholders, authority is more a matter of behaviour.

${ }^{6}$ See for example Giandomenico Majone, 'Europe's "Democratic Deficit": The Question of Standards' (1998) 4 European Law Journal 5-28
} 
non-starter; science itself has to continuously struggle to gain authority. ${ }^{7}$ Further, I shall argue that in the EU the mistaken understanding of science as a resource is particularly inappropriate-while elsewhere this may simply overtax science with something that it cannot deliver, in the $\mathrm{EU}$ it also brings to the fore the contradictions between Paneuropean science and the established national epistemic practices.

To distinguish Paneuropean and national science may appear shocking; indeed it goes against the Enlightenment tradition of universal science, where any scientific term, law or conclusion has the same meaning in each context and should be equally valid on both levels. There would not ever be a mismatch, except by an error, which could be easily rectified upon the very occurrence of the mismatch. The Science and Technology Scholarship (STS) have long since challenged this assumption and exposed how contextdependent science actually is. ${ }^{8}$ In a seminal case study, Brian Wynne demonstrated this dependency when the universalist claim of the 'scientific community' that certain radioactive isotopes will disintegrate within weeks proved to be invalid for the particular local conditions in Cumbria, UK, to a the greatest detriment to the local sheep population. ${ }^{9}$ More recently, the validity of the claim that a GMO maze cannot spread beyond certain fairly narrow perimeter appeared to be ascertained yet it proved to be unreliable when a few bee-colonies were introduced in the reference environment. ${ }^{10}$ It turns out that the truth of this claim depends not only on the biological characteristics of the GMO and the environment where it is grown, but also on the particular conventional

\footnotetext{
${ }^{7}$ Note the distinction between the claims authorities make on the basis of science and the claims for authority the science makes. I shall return to this below.

${ }^{8}$ Bruno Latour, We Have Never Been Modern (Harvester Wheatsheaf 1993), Sheila Jasanoff, Designs on Nature: Science and Democracy in Europe and the United States (Princeton University Press 2005)

${ }^{9}$ Brian Wynne, 'May the Sheep Safely Graze? A Reflexive View of the Expert-Lay Knowledge Divide' in Scott Lash and others (eds), Risk, Environment and Modernity: Towards a New Ecology (SAGE 1996). It turned out that all studies of the disintegration of the isotopes concerned were conducted for one type of soil, which was common everywhere but Cumbria.

${ }^{10}$ Javier Lezaun, 'Bees, Beekeepers, and Bureaucrats: Parasitism and the Politics of Transgenic Life' (2011) 29 Environment and Planning D: Society and Space 738-756.
} 
farming practices and existing patterns of human behaviour. The point of these examples is that 'science' is not something completely independent and external to the authority it is called to justify. Instead, expertise and authority are co-produced together in a stepwise fashion. ${ }^{11}$ This is not as radical as it may appear, if we do not forget that 'science' is not a set of propositions, which can circulate independently, but a practice which requires rigorous testing of such propositions. Although at certain level of generalisation science and governance are obviously two different human practices, a closer look shows that they feed into each other. ${ }^{12}$

The current controversy on the effect of certain pesticides on bee colonies offers yet another excellent example of the context dependency of expert conclusions. There are a number of factors which contribute to the decline in bee populations all over the world, and the main suspect are certain novel pesticides (neonicotinoides). In the US, after considerable public debate and rigorous scrutiny, the Environmental Protection Agency concluded that there are no sufficient reasons to single out the neonicotinoides. ${ }^{13}$ On this side of the ocean, the European Food Safety Authority (EFSA), after similarly rigorous scrutiny, made the opposite conclusion. ${ }^{14}$ The universalistic understanding of science would suggest that one of the two agencies must be wrong. However the case studies reveal that there is no apparent mistake in the methods employed by either but there are subtle differences in the expertise each of them employs and the factors they take into consideration. On the suggested understanding, such differences are legitimate and

\footnotetext{
${ }^{11}$ Note that this is not to say that science is produced by the authority - "policy-based evidence making" as cynics say; rather they both co-evolve and mutually stabilise each other. For a discussion see Sheila Jasanoff, 'The Idiom of Co-Production' in Sheila Jasanoff (ed), States of Knowledge: The Co-Production of Science and Social Order (Routledge 2004), the introduction by the editor.

${ }^{12}$ The common distinction between theoretical and practical knowledge reinforces the division science is believed to answer the question "what is?" while the domain of governance is "what to do"; each is believed to be the appropriate authority in the respective domain. But the related examples show that the answer to the "what is" question is context-dependent too.

${ }^{13}$ S. Suryanarayanan and D. L. Kleinman, 'Be(e)coming Experts: The Controversy over Insecticides in the Honey Bee Colony Collapse Disorder' (2012) 43 Social Studies of Science 215-240.

${ }^{14}$ Alberto Alemanno, 'The Science, Law and Policy of Neonicotinoids and Bees: A New Test Case for the Precautionary Principle' (2013) European Journal of Risk Regulation 191-207.
} 
sometimes must be tolerated. ${ }^{15}$ The important implication is that there is no neutral position and autonomous 'Science' to legitimate the claims of authority of organisations like the Codex Alimentarius Commission, Basel Committee on Banking Supervision, Global Gap or Forest Stewardship Council (FSC), or for that matter, the regulatory competences of the EU. ${ }^{16}$ Their expertise is produced by them to stabilise the authority claimed, and in turn that authority stabilises the science behind it.

This is not meant to be critical, especially if we remember that any authority depends on its social acceptance as authority. We would not find anything exceptional in the circularity in this case too. All that follows is that the claims of authority grounded in scientific expertise cannot be taken for granted; on the contrary, the expertise itself needs to be justified by references to something which is already trusted. One possibility is when the expertise is being produced locally, by institutions or practices which are trusted in the relevant polity. The other is when the transnational expertise includes the input from (trusted) domestic authorities and takes into account local circumstances. Conversely, the defiance of trusted practices and domestic consequences by universalistic science undermines the very authority this science is called to justify. It must be noted that denying that Science has a priori universal validity does not entail that international science has no bearing on the local; this will be parochial and plain silly. It only denies that such Science should be always taken for granted and cannot be challenged by local knowledge. As a matter of fact, all systems for production of science are open to input from outside, and in many cases this input may enjoy even more trust than the local

\footnotetext{
${ }^{15}$ Note that even if some differences are accepted to be legitimate, in some cases the need for a common decision may be paramount while others may allow differentiated solutions, which accommodate these differences.

${ }^{16}$ Which is, of course, with no prejudice to the political legitimacy the latter has, to the extent it has it. I have placed it in this list of quite different organizations, because they all do make claims on legitimacy on the basis of their expertise. For the EU see the early work of G. Majone.
} 
one. ${ }^{17}$ But even in such cases, the universalistic claim acquires its local authority via the local practice.

The reader may be ready to agree with the basic thrust of this argument, but find it too sweeping to accept when I speak about 'science' failing to confer authority to regulation. Indeed, it is problematic to speak about science in the singular, as science is a practice, carried out by many different people and institutions. Further, any scientists worthy of her salt will be very careful to define the 'scope of their research'. She would add a list of disclaimers and identify the limitations of her method and the conditions for validity of her scientific claims. If confronted, she would readily acknowledge a number of further assumptions, which were not mentioned but implicit nevertheless. Yet, it is justified to speak about science in the singular, as this is the way it is usually construed by the authorities that seek to rely on it.

Relatively few are the scientists venture beyond the narrow confines of the 'scope of research' themselves and do claim authority that squarely qualifies as political. The assertion that something is 'safe' and societies must accept as conclusive their judgement on the issue is such a claim to authority. For example, in 2014, a group of 21 prominent scientists signed an open letter to the European Commission that 'Europe must allow prompt authorization of genetically modified plant varieties that have been found safe by the competent authority following a thorough science-based risk evaluation' ${ }^{18}$ As the current regime does make scientific evaluation pivotal for the authorisation, this letter is in practice making the claim that it is for the plant scientists to be the ultimate authority on the question whether a GMO variety should be cultivated and marketed in Europe or not. Certainly scientists have a legitimate interest to call for the adoption of the

\footnotetext{
${ }^{17}$ The best example is Canada, where there is a statutory preference for preference for using 'nondomestic' regulatory standards and the development of unique national ones needs to be justified, see Jacco Bomhoff and Anne Meuwese, 'The Meta-regulation of Transnational Private Regulation' (2011) 38 Journal of Law and Society 138-162.

18 'Genetically Modified Crops: An Open Letter to Europe', The Telegraph, 30 October 2014.
} 
technology and can make an indispensable contribution to an enlightened decision, but they are only stakeholders, not the judges. Even those scientists who do not claim authority in such an overt way often do so implicitly because, pace Hume, in many contexts even purely descriptive statements have clear normative connotations. This will be the case if, in the above example, a scientist has not signed the petition, but asserts in public that 'GMOs are safe'; in the context of the currently prevailing mode of sciencebased regulation 'safe' implies that it should be permitted. ${ }^{19}$ A more nuanced look would question how safety is defined-after all, safety is not a natural phenomenon, but a human category. The microbiologist may be the appropriate authority on the question whether certain number of rodents will die under certain conditions but this is not equal to stating that the conditions are 'safe'.

The scientists may be excused if they are making this leap inadvertently. Political authorities should be careful not to. If the relevant publics to which they are accountable consider other factors to be also relevant - such as the safety for the existing farming practices - they are well advised to take them into account. However, even if most scientists are not complacent folks and would make their best to avoid such leaps, the science-based regulation regimes often do. As Asselt and Vos observe, science is called to support decisions precisely in the areas of uncertainty, and its uncertainty is readily acknowledged yet paradoxically it is employed by the regulators to provide certainty. ${ }^{20}$ The risk assessments are taken as plausibility proofs, which allow the

\footnotetext{
${ }^{19}$ In the same vein the apparently descriptive statement "More than 200000 people have died in the civil war in Syria" contains an implied judgement which no one would fail to infer.

${ }^{20}$ See Marjolein B. A. van Asselt and Ellen Vos, 'The Precautionary Principle and the Uncertainty Paradox' (2006) 9 Journal of Risk Research 313-336, Marjolein B. A. van Asselt and Ellen Vos, 'Wrestling with Uncertain Risks: EU Regulation of GMOs and the Uncertainty Paradox' (2010) 11 Journal of Risk Research 281-300, Marjolein B. A. van Asselt, Ellen Vos, and Bram Rooijackers, 'Science, Knowledge and Uncertainty in EU Risk Regulation' in Everson Michelle and Ellen Vos (eds), Uncertain Risks Regulated in National, European and International Contexts (Routledge Cavendish 2009).
} 
authorities - generally uneasy with uncertainty_to interpret the available pieces of evidence in a way that provides certain grounds for their decisions. ${ }^{21}$

Having made a number of bold normative claims, in the next section I will discuss in some detail the recent history of the regime of GMO regulation in the EU, which is a perfect example how the reliance on best available science failed to confer authority to the regulatory regime. In section three I take a closer look at three different local systems of production of knowledge whose claims for authority are generally accepted, and I shall argue that in a transnational system they should be respected. ${ }^{22}$ Obviously, this runs against the scientism-based harmonisation model, which is prevalent in the EU. The same model is common in other transnational regimes yet there seem to be precious few examples where transnational authorities managed to build their authority by a more inclusive approach. In the final section I shall consider several possible ways to accommodate the need to justify the science generated at Paneuropean level for the purposes of uniform regulation and to give the due respect to national epistemic models

\section{HISTORY OF A FAILURE}

The current regime of GMO authorisation in the EU resulted from the settlement of a heated controversy between and within the member states in the late 1990s and a de facto moratorium on any new GM authorisations lasting from 1998 to 2004. As the BSE ('mad cow') crisis has eroded the trust in both national and European institutions, expertise was explicitly called for on the assumption that trusted science will confer trust to the science-

\footnotetext{
${ }^{21}$ Van Asselt and Vos provide excellent examples of the different ways the Commission frames EFSA's terms of reference and treats the results, see Marjolein B. A. van Asselt and Ellen Vos, 'EU Risk Regulation and the Uncertainty Challenge' in S. Roeser and others (eds), Handbook of Risk Theory (Springer 2012).

${ }^{22}$ Sheila Jasanoff, 'Epistemic Subsidiarity - Coexistence, Cosmopolitanism, Constitutionalism' (2013)

2 European Journal of Risk Regulation 133-141.
} 
based decisions too. ${ }^{23}$ As Levidow and Carr note, in order to manage the conflict on GMOs "the Commission invoked 'science-based regulation', implicitly equating science with advice from EU-level expert bodies". ${ }^{24}$

This is very much in line with the well-established tradition. The whole history of the Union is about decisions being taken away of the political authorities and entrusted to supranational expert bodies. The same approach was employed across the board for regulation of other areas and the first decade of the century saw a proliferation of EU agencies:

The independence of their technical and/or scientific assessments is, in fact, their real raison d'être. The main advantage of using the agencies is that their decisions are based on purely technical evaluations of very high quality and are not influenced by political or contingent considerations. ${ }^{25}$

Unlike their American counterparts, most of the EU agencies do not have formal authority to regulate, and their role is merely to provide advice to the Commission and the other Treaty bodies. Yet it was anticipated from the very beginning that the new GMO regime seeks to put EFSA in a position of 'normative authority':

Whilst the Regulation anticipates that the Authority will have no direct regulatory authority, it anticipates that it will, however, have considerable

\footnotetext{
${ }^{23}$ For example Recital 9 of the General Food Law (Regulation 178/2002) explicitly links confidence in the decision-making with its scientific basis (as well as independence of decision maker).

${ }^{24}$ Les Levidow and Susan Carr, 'Channelling Participation, Testing Public Representations' in GM Food on Trial (Routledge 2010), 144. This is what allows the critics to talk about 'science' in the singular, which is obviously justified only in this context.

${ }^{25}$ Communication from the Commission - The operating framework for the European Regulatory Agencies, COM (2002/0718 final), emphasis added. The dichotomy between technical on one hand and poliical or contingent which is being constructed by the commission is remarkable.
} 
normative authority, so that its rulings will nevertheless structure individual and institutional choices on food safety within the European Union. ${ }^{26}$

To expect that EFSA will become a normative authority, one must assume that it will be derived from its scientific excellence, for it was not provided with any other sources to build this authority on. ${ }^{27}$ This role of science is not confined to the GMO area, as Article 6 of the General Food Law Regulation, established the principle of science-based regulation. It also established the traditional division between risk assessment (RA) and Risk Management (RM), where 'risk assessment shall be based on the available scientific evidence and undertaken in an independent, objective and transparent manner' while 'risk management shall take into account the results of risk assessment, and in particular, the opinions of [EFSA], other factors legitimate to the matter under consideration and the precautionary principle'.

Under the established GMO authorisation procedure the risk assessment is entrusted to EFSA, ${ }^{28}$ but in theory Member States have opportunities to engage actively both in the assessment process by submitting their own evaluations and in the management through their representation in the committee of national representatives (or the Appeal Committee) ${ }^{29}$ Formally, EFSA is in no way superior to national (or any other) expert authorities; they are all peers as they should in the republic of science. Yet it

\footnotetext{
${ }^{26}$ Damian Chalmers, "“Food for Thought”: Reconciling European Risks and Traditional Ways of Life' (2003) 66 Modern Law Review 532-562, 540.

${ }^{27}$ Elsewhere I argue that EFSA has become the de facto decision maker on the GMO issues, however this is not because it is accepted as a normative authority, but because of institutional impasse, see the author (n 1) .

${ }^{28}$ The authorisation of GMO for cultivation is governed by the Directive 2001/18/EC on the Deliberative Release in the Environment of GMO, hereinafter 'Deliberative Release Directive.' If the GMO is to be used for food or feed, it must be authorised under Regulation (EC) 1829/2003 on GM Food and Feed, hereinafter 'Food and Feed Regulation.' Under the latter its safety must be always assessed by EFSA. Under the former this is necessary only in case some member state has concerns, which is always the case, so EFSA plays a key role in both cases.

${ }^{29}$ For details see Regulation (EU) No 182/2011 laying down the rules and general principles concerning mechanisms for control by Member States of the Commission's exercise of implementing powers. Under the pre-Lisbon comitology rules in case the committee fails to decide the issue was referred to the Council. This is no longer the case, and it is referred to the Appeal Committee, which also consists of national experts.
} 
is supposed to gather all expertise so that the regulatory decisions are informed by all relevant data available. ${ }^{30}$ This is to be achieved by the "networking of risk assessors through agency structures [which invite] national perspectives on risk into the EU system ${ }^{31}$ with EFSA in the centre. This is a sophisticated, even Bayesian, regime, which is apparently reliant on the assumption that differences of opinions between EFSA and the national expert authorities are due to differences in the available information. Therefore, if all relevant information is made common knowledge the opinions are expected to converge:

Where the Authority identifies a potential source of divergence, it shall contact the body in question to ensure that all relevant scientific information is shared and in order to identify potentially contentious scientific issues. ${ }^{32}$

This is clearly the universalistic understanding of scientific knowledge, even though the regime recognises possible divergence of scientific information it is aimed at reaching a single 'right' conclusion based on it. Differences in the opinions are presumed to be only temporary and due to lack of information, which can be remedied by sharing it. This view does not allow for decisions, which are tailored to accommodate the local concerns. ${ }^{33}$ This may be an adequate response to the imperatives of free movement in the single market, but very inadequate to the context dependency of knowledge and local generation of scientific authority I argue for in the present paper. ${ }^{34}$ Notably, it does not allow for

\footnotetext{
${ }^{30}$ There is a special regulation on this, see Commission Regulation 2230/2004 laying down detailed rules for the implementation of Regulation No 178/2002 with regard to the network of organisations operating in the fields within the EFSA's mission (23 December 2004).

${ }^{31}$ Lee, EU regulation of GMOs (n 20), 68.

${ }^{32}$ General Food Law Regulation, art. 30 (2).

${ }^{33}$ For more details on the regime see Vesco Paskalev, 'Can Science Tame Politics: The Collapse of the New GMO Regime in the EU' (2012) 4 European Journal of Risk Regulation 190-201. I have borrowed the last few paragraphs from this work.

${ }^{34}$ One may argue that accommodation is a matter of risk management which is triggered only after the risk assessment. But here is the catch - when the conclusion of the risk assessment is unqualified safe, no risk management can be triggered. On this see van Asselt and Vos, 'The Precautionary Principle and the Uncertainty Paradox' (n 20).
} 
different interpretations of the same evidence, which are actually quite common in both hard and applied science. A recent example of this is the possible cancerogenicity of Glyphosate which is a very common herbicide. On the basis of the very same study of mice, conducted as early as 1985 the American EPA decided that the pesticide might cause cancer. In 1991 it re-evaluated the same study and authorised its use. In 2015, the International Agency for Research on Cancer (IARC), relied on the same study to classify it as 'possibly carcinogenic' which can prompt another round of reassessments by the agencies around the world. ${ }^{35}$ Although such episodes are common in science, for Science as the EU conceives it, this is an unacceptable anomaly.

The other problem is that under the existing regime it is for EFSA alone to set the scope of the assessment and to determine what counts as 'scientific.' This allows it to be selective; whatever it determines to be not a scientific issue cannot be taken into account. In practice this means that the assessments would be based mostly on laboratory tests about the safety of the technology and they are inevitably provided by the industry. Obviously, these are not the only things, which citizens care about when they have to choose whether a new technology is to be adopted. They also care about its socioeconomic impacts, cost of co-existence, effect on national health and dietary policies, preservation of existing farming practices and consumption patterns, environmental policy goals, agricultural policy, town and country planning, lock-in effect. In theory, these 'other factors' are recognised as legitimate basis for the decision to authorise or not a new GMO variety for cultivation or marketing. ${ }^{36}$ However, EFSA does not take most of these into consideration as in view of the microbiologists who sit on its GM panel, they are political and not scientific issues. The exclusion of such considerations however

\footnotetext{
${ }^{35}$ See 'Weed Killer, Long Cleared, is Doubted', in The New York Times, 27 March 2015.

${ }^{36}$ Mihail Kritikos, 'Traditional Risk Analysis and Releases of GMOs into the European Union: Space for Non-Scientific Factors?' (2009) 34 European Law Review 405-432.
} 
makes EFSA's opinions largely irrelevant for the people and the member states for which these issues are the most important ones.

The exclusion of such factors is bound to make the assessments irrelevant for all citizens (and member states) who consider them important for their decision on the riskiness of the technology. Indeed, EFSA's opinions failed to generate any support for the proposed authorisation. Its assertions of safety could not ever persuade any Member State unless it was already in favour to the authorisation from the beginning. Its opinions seem to matter only for the Commission, which uniformly defers to their conclusion and considers itself bound to authorise whatever EFSA pronounces as safe. ${ }^{37}$

On the basis of EFSA's advice the Commission submits a proposal to the committee of national experts, the so called comitology mechanism. The committees may vote-by qualified majority vote as is the custom in the EU-either way, and it is supposedly free to take into account the other legitimate factors, which have been left out of the assessment. The problem is that if they fail to adopt any decision, the Commission in empowered to adopt it itself. Comitology is famously consensual process, ${ }^{38}$ and is largely deferential to the Commission's proposals yet on this issue, for the decade since the GM regime is in place, it failed to yield any decision in all cases. ${ }^{39}$ More importantly, in the face of the implacable opposition, the Commission often blinks and keeps on returning the dossiers back to EFSA for more information. EFSA routinely repeats its conclusions and the Commission eventually feels compelled to follow. ${ }^{40}$ Any decision on the matter takes years, and even when finally adopted, member states remain unconvinced and employ various tactics to avoid implementation. So far there are about a

\footnotetext{
${ }^{37}$ See its own admission in the recent Commission's GM Review (n 1).

${ }^{38}$ Christian Joerges and Jurgen Neyer, 'From Intergovernmental Bargaining to Deliberative Political Processes: The Constitutionalisation of Comitology' (1997) 3 European Law Journal 273-299.

${ }^{39}$ The GM Review admits that all decisions have been adopted 'without the support of the committees.'

${ }^{40}$ The Commission has always insisted that it is legally obliged to do so (see the GM Review, $\mathrm{n} 1$ ).
} 
dozen GMOs authorised for marketing and only one has been authorised for cultivation BASF's starch potato Amflora - and the decision was annulled by the General Court in December $2013 .{ }^{41}$

This record suggests that the European GMO regime is a remarkable failure, even though the decisions seem to have been based indeed on the best available science and incorporated all available information (at least no challenge purportedly supported by 'new evidence' has ever succeeded). It is a failure in several ways. It is failure in view of the biotech industry, as the regime failed to permit trade or cultivation when requested, or does so after immense delays, which deter new applications. But it is a failure in view of the opponents, because it fails to prohibit what many have grounds to believe is risky. The failure to decide anything is an abdication of regulatory responsibility and violation of the rule of law, which was dully condemned by the General Court on a number of occasions. What is important for the present study is that the failure to decide cannot gain authority for EFSA or the system as a whole. On the contrary - it is bitterly criticised from both sides in the wider GMO debate. This failure brings home the point that authority cannot be gained by reliance on Science alone, but scientists themselves needs to struggle to gain it. In the apt phrase of Levidow and Carr, EFSA was meant to become the arbiter in the controversy, but it found itself on trial. ${ }^{42}$ I would add that the proposals to allow member states to opt-out of the regime can be considered as the judgement in this trial, and it is not favourable to EFSA and the adopted understanding of science.

Perhaps even more striking is the failure to reform the regime. It is suggestive that the first amendment proposal was made in March 2010, upon the announcement of the first (and so far only) authorisation of a GMO for cultivation since the 90s. The Commission recognised that the institutional impasse and that a number of Member

\footnotetext{
${ }^{41}$ Case T-240/10 Hungary v. Commission [2013].

${ }^{42}$ Les Levidow and Susan Carr, GM Food on Trial (Routledge 2010).
} 
States remain unconvinced of the safety assessments, and proposed to allow to such states to prohibit cultivation of authorised GMOs on their territory. Notably, it did not propose any amendment to the regime itself to break up the stalemate or improve the confidence of the recalcitrant states. ${ }^{43}$ The proposal itself raised some controversy and was adopted only five years later. As soon as this amendment entered into force, the Commission introduced a new proposal to allow to the Member States to prohibit also the use of authorised GMOs on their territory. These is an important step back when the Commission proposes to devolve certain powers to the Member States. This comes as a recognition that there is a problem, both with the lengthy process of decision-making and with the lacking legitimacy to force GMOs upon the states which remain unconvinced by the assessment, notwithstanding the unconditional support of the 'best science' embodied by EFSA. The conclusion that science cannot be used as a resource to confer trust to authoritative decision is obvious, but the Commission does not seem to see any problem with its understanding of science - too narrow to account for the factors people actually care about and too universalistic to be sensitive to contextual factors. As the Commission declared that it is ready to respect the choices made by Member States on whether or not to authorise GMO on their territory, in the same time it stated its intent to keep the existing regime 'intact' and to guarantee that any decision adopted was based entirely on independent scientific advice, in particular that of EFSA. Apparently, it gave up on authority-building and now agrees that Member States should be legally allowed to disagree. But it does so for prudential reasons only and obviously it is not ready to respect the validity of any other scientific claims except those of its own advisor. ${ }^{44}$ The understanding behind these not very coherent intentions seems to be that everything

\footnotetext{
${ }^{43}$ The exceptions are some efforts to make EFSA more transparent under the mounting pressure of a number of environmental organisations and the resignation of its head in 2012 upon discovery of conflict of interests.

${ }^{44}$ Both the cultivation ban and the use ban can be introduced on grounds, which do not conflict with the scientific risk assessment conducted by EFSA.
} 
scientific shall belong to EFSA, while the member state can justify their decisions on other, i.e. non-scientific reasons. This could be convenient pragmatic solution, if it was not placing the national bans based on 'non-scientific reasons' on a collision course with other regimes of science-based regulation, especially the WTO and possibly with similar requirements in their own national laws. ${ }^{45}$

In sum, in the face of a very controversial issue, the EU tried to bridge the division between the Member States by making scientific risk assessment by an independent advisor pivotal for the decision. But the established regime failed to reduce the controversy-the Member States that were sceptical remain unconvinced and the division is as deep as ever. It is apparent at all stages of the process but is most visible at the stage of the committee of national experts, which never succeeded to adopt any decision, either way. It is suggested that reason for this failure is the way science was employed by the regime. ${ }^{46}$ While there may be other factors which contributed to the failure, it is hard to see what is the value added of the scientific risk assessments in the way they are conducted and employed on this issue today. There is no way to measure whether the GMO regime or EFSA gained any trust of citizens, governments or stakeholders, but the persistent stalemate is an indication that their claim to normative authority was not very successful, to put it mildly. By proposing the opt-outs the Commission may seem to have given up on the claim for authority of the system it manages, yet its insistence that bans should be on the ground of reasons not addressed by EFSA show that it is far from it.

\section{EPISTEMIC SUBSIDIARITY}

\footnotetext{
${ }^{45}$ The proposed national bans on use was unique in uniting Greenpeace and Europa Bio against it, see Euractiv, 'EU Proposal on GMO Food Criticised by Greenpeace, Industry', 22 April 2015. All major party groups in the EP are against it and the plenary is expected to vote overwhelmingly against the proposal in the autumn of 2015 .

${ }^{46}$ Note that this is not to say that 'science' has failed, only an unnecessarily narrow version of it, which was implemented poorly by the rigid separation of risk assessment and risk management.
} 
The present short article cannot state whether the tortured history of the GMO regulation in the EU is an exception from a generally smooth regulatory system or a symptom of the general failure of the EU regulators to justify their claims to authority. But whatever the case, it is telling that the overwhelming reliance on universalistic and exclusionary scientific expertise cannot be easily exploited as a source of authority. Various other studies have demonstrated how scientific authorities, when trusted, has worked hard to earn their recognition ${ }^{47}$ but the EU is generally oblivious to these.

Sheila Jasanoff observes that "[n]ations differ systematically in their strategies of public reasoning - that is, how policy-relevant knowledge is generated, how is it evaluated for policy purposes, how scientific disputes are resolved, and how lay publics are engaged in decision-making, ${ }^{48}$ She further argues that people's preference for styles of reasoning ought to be accorded the same kind of protection that we accord to a state's constitutional choices. ${ }^{49}$ This principle of respect of the preferred modes of public reasoning Jasanoff calls epistemic subsidiarity.

Thus, the accepted model for establishment of policy-relevant facts in the US is adversarial proceedings, where the most qualified experts are called to give evidence. In Germany, such facts are trusted when established through deliberation between the relevant authorised institutional representatives. In the UK, the same issue must be established by identifiable senior 'safe hands' who are experts but also believed to be capable of discerning the public good. ${ }^{50}$ While in Germany public reason aims at a 'view

\footnotetext{
${ }^{47}$ For a wonderful example from the Netherlands see Frank Huisman, 'Expertise and Citizenship. The Organization of Trust' in Performing Expertise. Scientists between State and Society, 1860-1960, vol. 1960 (Pickering \& Chatto 2014). The author studies how the Dutch pharmacists struggled to gain recognition for their expertise and associated power, and, notably, how it is waning today when they are used to take them for granted. For more pertinent examples in transnational cases one should look no further than the article of Jaye Ellis in this symposium.

${ }^{48}$ Jasanoff, 'Epistemic Subsidiarity' (n 22), 134.

${ }^{49}$ Ibid, 136.

${ }^{50}$ Ibid, 140. Note how much this differs from the science-only approach adopted in the EU.
} 
from nowhere', in UK the goal is rather a 'view from everywhere' ${ }^{51}$ Following their own ways, in the debate on GMOs, the different countries have reached different substantive positions. In Britain a wide participatory public consultation was organised under the heading GM Nation?, which focused on the public engagement in technological governance. ${ }^{52}$ By contrast, in Germany the debates revolved on the responsibility of the state, and its ability to set clear safety standards. In Austria the debates focused on the autonomy of choice of the nation, which apparently was crucial for its current firm antiGMO stance. In the US, the debate on GMO was strongly influenced by earlier debates on nuclear safety, so the main concern was of containment of the risk of release in the environment. When the debates in each of the separate public spheres lead to the selection of certain considerations as relevant for the issue, and at a certain conclusion which reasonably follows from these concerns, it becomes very difficult to challenge them with any evidence from without. As it is well-known from experimental psychology, deliberating groups tend to polarize. ${ }^{53}$

The robust response to this divergence of epistemic practices is constitutionalism. ${ }^{54}$ The term is used here in the sense that it requires 'recognition, within and between nations, of fundamental decision-making principles that may never have been explicitly articulated in law and policy'. ${ }^{55}$ While EU institutions, courts and academics have paid a great deal of attention on the constitutional rights and the

\footnotetext{
${ }^{51}$ Ibid, 141.

${ }^{52}$ See more details in Robert Doubleday and Brian Wynne, 'Despotism and Democracy in the United Kingdom: Experiments in Reframing Citizenship' in Sheila Jasanoff (ed), Reframing Rights: Bioconstitutionalism in the Genetic Age (MIT Press 2011).

${ }^{53}$ Cass R Sunstein, 'The Law of Group Polarization' (2002) 10 Journal of Political Philosophy 175 195. I have already discussed the implications of group polarization in the EU context in Vesco Paskalev, 'Network for a European demoi-cracy: Are the national parliaments up to the job?' (2011) 7 Croatian Yearbook of International Law and Policy 43-67 and Vesco Paskalev, 'Portrait of the EU as a Rational Man: Collective Reason and Democratic Deficit', 2012, EUI Working Papers, Law No 19.

${ }^{54}$ Jasanoff identifies three modes to respect epistemic subsidiarity - co-existence, cosmopolitanism and constitutionalism, but only the latter is sufficiently robust to be normatively acceptable.

${ }^{55}$ Ibid, 140.
} 
constitutional separation of powers, and have elaborated sophisticated theories to accommodate them, they have been largely oblivious to the constitutional position of science, implicitly accepting that scientific claims move freely across borders without any prejudice to their validity. Let me be clear, scientific claims do travel across borders, but outside of the context of their production they tend to lose their robustness. A laboratory experiment may prove that a GMO is 'safe' in the US, but in Austria it is just that - a laboratory study. The acceptance and the meaning of such claims are mediated by the local epistemic models and depend on how they fit in the local epistemic horizon.

Let us briefly discuss the outlined mode of public reason in the EU and its relationship with that of the member states in the light of this. Subsidiarity is a fundamental principle of EU law for decades, yet ironically, the call for its application on this issue comes from an American, who is not an integration scholar. The Commission does mention subsidiarity as a justification for its proposal to allow national bans of GMOs, but it did not feature prominently anywhere in the discussions of the proposals that followed. As we saw EFSA is required to cooperate with the national authorities, but it has only to acquire the information it needs, so that it can issue its opinions on the basis of 'all' and 'best' relevant information. For it, the national agencies are merely sources to draw upon, not authorities to reckon with. Epistemic subsidiarity calls for communication and respect in both ways, while the upper level still will often legitimately prevail it should try to accommodate the concerns of the lower level and never dismiss the concerns raised there as irrelevant. EFSA's mandate to take into account scientific, and only scientific information, allows it to define unilaterally what counts as science and dismiss any considerations which do not fit, regardless of their status in the national system of public reason. ${ }^{56}$ Thus, although the established GMO regime is institutionally

\footnotetext{
${ }^{56}$ One need not fear that this will provide an easy avenue for junk science; epistemic subsidiarity requires respect only for what passes through the sieve of the established epistemic practices in the respective nations.
} 
open to cooperation with member states, it is substantively closed to most of their actual concerns.

Paradoxically, the existing exclusionary approach makes the regime less scientific. While the rigour of the scientific method is much welcome in the area, its essence is reductionist: in order to estimate certain causal effect, the risk assessor would reduce the immense variability of natural and social systems to a few variables which are easily mapped, modelled and measured ${ }^{57}$ However, if the conclusions are to be valid also outside the lab, account should be taken of the circumstances in the real world, which vary from a location to another. Besides making the assessment more scientific, the sensitivity to local knowledge will also generate trust in the decisions based upon it. The governing rule should be inclusion of all sides as co-equal, and by allowing to everyone to argue on their own terms, rather than by exclusion of some claims as "political or contingent' or by requiring the stakeholders to adopt the discourse of the industry to appear scientific.

Interestingly, there is a growing understanding that expert judgements are valueladen and non-neutral and that science cannot deliver certainty. ${ }^{58}$ Recognizing there is a problem with the claims to authority of the regulatory system, in 2006 DG Research commissioned a team of STS scholars to address the problem of 'European public unease with science'. ${ }^{59}$ The study concluded that there is no general disaffection with science, but selective disaffection with particular fields thereof. The study found that the EU public has actually become a prominent participant in science-based regimes, and also that the role of European non-governmental actors in production of science and

\footnotetext{
${ }^{57}$ Sheila Jasanoff, 'Relating Risk Assessment and Risk Maangement: Complete Separation of the Two Processes is a Misconception’ (1993) EPA Journal 37.

${ }^{58}$ Maria Lee, EU Environmental Law (2nd edn, Hart Publishing 2014).

${ }^{59}$ Ulrike Felt, Brian Wynne, and Michel Callon, 'Science \& Governance: Taking European Knowledge Society Seriously' (IPOC 2007)
} 
technology is increasing. ${ }^{60}$ It recommended a shift away from the innovation-focused science, which is currently overwhelming, towards more 'socially distributed, autonomous and diverse collective forms' ${ }^{61}$ Importantly, the study also found that 'public concerns tend to focus not only on narrow prediction of probabilities, but also on neglected or unknown (thus unpredicted) effects on society, and the institutional incapacity to deal with such effects'.

The last point qualifies my claim in this paper, that science by itself does not justify authority in two ways. First, the question of 'safety' cannot be decided without taking into account the broader societal implications of new technologies. Keeping them outside of the domain of the assessment does not make the assessment scientific, it makes it redundant. You cannot decide that a pesticide is safe for environment if you do not know whether it is actually used in dosage and cumulative amount, which does not inflict any harm to it. While regulators may be 'blinded by science', citizens are not. The second qualification, related to the first one, is the relationship of mutual stabilisation between science and authority, which is the question of what is 'safe' is not independent of the question of the capacity of the authorities which handle the issue. This complementarity renders any definitive 'scientific' assessment of risk superfluous. As the bodies which implement the European regulations are generally national, the issue harkens back to the Member States. So it would be gross simplification, and often plain wrong to claim that the problem is of the bad EU impinging upon national diversity. A technology, assessed as safe by the responsible European institution on the basis of best international research, may be perceived both as safe, if in a given Member State it is to be handled by an authority which is highly trusted, and as unsafe, if under the national law another

\footnotetext{
${ }^{60}$ This development may be attributed to the established scientistic paradigm, which Holder and Lee describe as 'fight science with science', Jane Holder and Maria Lee, Environmental Protection, Law and Policy, 2007.

${ }^{61}$ Felt, Wynne, and Callon, ‘Science \& Governance' , (n 61) 10.
} 
authority is competent, which is not so trusted. Thus, the finding of the transnational assessment may be resented or welcomed, depending on its fit with the domestic institutional capacity. ${ }^{62}$

There is a relationship of complementarity also between technology and established patterns of human behaviour, i.e. farming practices. The chlorine-washed chicken, which has become the symbol of the protesters against the proposed Transatlantic Trade and Investment Partnership (TTIP), provides an excellent example. In the US, slaughtered chicken are commonly rinsed with chlorine to disinfect from pathogens such as salmonella. Thus, this is a technology to make poultry safer for consumer. In the EU, however, this treatment has been banned in the 90s for fear of possible cancerogenicity and potential to breed resistance in bacteria. Instead, the consumer safety in Europe is based on early testing of live chicken and requirements for hygiene of the poultry farms (which is in line of the EU integrated approach to food safety 'From Farm to Fork'). Thus, the European method required significant investments from the poultry farmers and took some 20 years to give effect, but recently the instances of illness decreased dramatically (while still a bit higher than the US, which plateaued for the same period). ${ }^{63}$ All in all, both methods work but fail to eliminate risk completely, so the question whether the chlorinated chicken is safe for consumers is bound to have different answers on the two sides of the Atlantic. If the European ban on chlorine bath is introduced by a transnational regulator across the board, the Americans will be exposed to much higher risk of chicken-borne infections and improving production hygiene will take years to give results. On the other hand, if the chlorine-wash is to be introduced on this side of the pond, Europeans will be exposed to additional risk of cancer, without

\footnotetext{
${ }^{62}$ I shall revisit the issue of domestic institutional capacity in the end of the final section.

${ }^{63}$ Jennifer Mcentire, 'Footborne Illness: How the U.S. and Europe Compare', The Acheson Group, available at http://achesongroup.com/2014/03/foodborne-illness-us-eu-compare/ (last accessed 31 August 2015).
} 
much to gain in terms of disinfection. It is important to note also that the safety of the non-chlorine-washed chicken depends on a number of established human practices not directly related to the chlorine treatment itself. If the EU accepts the American claim about the safety of the chlorine bath, the European poultry farmers will be under competitive pressure to change their own practices. To put it short, somewhat risky disinfection technology neatly complements low-hygiene farming, but high-hygiene farming allows to do away with it. Scientists are indispensable to define each these options, but the choice is not for them to make.

The broader claim before the particular example is that there is a relationship of complementarity between technology and established patterns of human behaviour. As technologies and substances with zero risk are virtually non-existent, safety is always a matter of degree and expert advisors often conclude that something is safe on the condition that it is 'used according to the prescription'. The obvious complication is that actual safety will depend on the usage patterns just as much as the scientific pronouncement. Thus, safety is a matter of complementarity - one society may be safe when the technology is complemented by the appropriate inspections, another society may achieve safety by less reliable law enforcement system and avoidance of technologies it may be unable to control. It is important to emphasise that the difference is not a matter of degree of development, law-abidingness or corruption, but a choice. The latter society shall not be expected to 'develop capacity' and eventually adopt the technology; whether it will do so is only an option it may prefer not to take.

One may think that the growing recognition that there is no bright line between Science and the 'other' will have undermined the rigid institutional separation of risk assessment from risk management, however the latter not only continues to prevail, but is 
sometimes considered to be the appropriate response to the blurring of the boundaries. ${ }^{64}$ The persistence of the RA-RM pattern as well as the numerous references to the 'best available scientific expertise' which pepper the acquis now show that the EU regulation is stuck with the unreflexive stance towards the validity claims of purportedly universal Science. Scientism remains the underlying principle in the strategy of public reason in the EU and leaves little, if any, space for respect to national strategies.

\section{SOLUTIONS TO THE MULTILEVEL CHALLENGE}

Having argued for the need for epistemic subsidiarity in the EU if it is to add to its authority, does it mean that the deference to national modes of public reason is the ultimate answer? I think no. Notwithstanding the need to accommodate as much as possible, the EU has to adopt at least sometimes Paneuropean standards and they will at least sometimes have to override local concerns. To claim authority for such cases, the EU, as well as other transnational regulators, needs to have a strategy of public reason of their own. Let me restate the problem discussed in this paper: there is wide recognition that authorities, public or private, at various levels need to be informed by science. However they find themselves between at least two sets of competing claims - these which easily travel across borders, and claim authority on the basis of their international recognition, and those which are generated by trusted local institutions, and claim authority on account of their fit to the local context. I submit that in case of contradiction, there cannot be a general rule according priority to either. The EU is in a position to mediate between the two, ${ }^{65}$ and decide what to follow on a case by case basis. There are three considerations, which may guide this selection of the appropriate authority for each

\footnotetext{
${ }^{64}$ For an elaborate discussion of the problem with the rigid separation, and its alternative see Elizabeth Fisher, Risk Regulation and Administrative Constitutionalism (Hart 2007).

${ }^{65}$ Compare with Oren Perez, 'The Hybrid Legal-Scientific Dynamic of Transnational Scientific Institutions' (2015) European Journal of International Law 1-34 who views all transnational scientific institutions as such mediators.
} 
case. These are social robustness of knowledge, path-dependency and comparative institutional capacity. In this final section I shall discuss them in turn.

Note that, notwithstanding my previous arguments, there need not be always contradiction in the first place. Domestic scientific practices of industrial nations are not, and have never been completely isolated from the rest of the world. On the other hand, when universalist science takes care to make explicit all of its initial assumptions, the limits of its validity in certain context become easily identifiable. Writing a full list of such caveats may be a daunting task, but is not impossible at least as a principle to aim at, and is necessary if the particular piece of expertise aims to enjoy free movement rights. While every scientists must do her best to begin the list, it may not be necessary complete it herself, her opponents will be quick to emphasise all the limitations thus finishing it for her. Suffices to make the regulatory process open to allow for scientific claims to be challenged on their assumptions. As simple as this appears, contestations of the basic assumptions are generally excluded by the legal framework, even if scientists themselves are ready to hear them. The predominant system of risk analysis divides risk management from risk assessment so that only the conclusions of assessments are taken on in the management; the assumptions are confined to the domain of the assessors. The institutional separation allows to the experts also to determine what constitutes science and what not, which makes difficult for the managers to consider things that the scientist themselves would think outside of their competence. Allowing early contestation, at the phase when the advisor terms of reference are written is a possible solution. Thus, each side can benefit from the critical engagement of the other: the contestors would have an opportunity to have their concerns heard, and the authority gets a better chance to end up with a claim that is acceptable. Where the two sides contradict most often is in the definition of what qualifies as a problem. As stated times and again, the understanding of science underlying the regulatory regimes of the EU excludes as unscientific far too 
many circumstances which are nevertheless locally important. As they may be taken into account by the local epistemic practices ${ }^{66}$ its their claims to authority will enjoy support, while those of the EU will be unacceptable for the respective publics ab initio. If the scientific claims from the higher level are to be trusted, and for their claim to authority to pre-empt that of the local, the former must be open to take into account the particular circumstances and the particular concerns of the latter. When talking about 'circumstances' this claim is uncontroversial — indeed it may be even trivial to say that the scholarship on radioactivity must take into account the chemical consistency of the Cumbrian soils to make valid statements about the safety of pastures in Cumbria. It becomes less clear however, when we want the expert advisor to consider the need for alternative feed for the Cumbrian sheep while, pending the assessment, pastures are quarantined. Yet this is what any authority which declares quarantine must include in the equation. In a more recent example, in the process of authorisation of the Amflora potato, one dissent to the EFSA opinion noted that even though the probability of horizontal transfer of antibiotic resistance is low, 'given the magnitude and multitude of exposures from the foreseen use of [Amflora], it appears the cumulative probability of transfer could range from unlikely to high' ${ }^{67}$ Apparently the position within this range depends on considerations of scale of production, which the majority of the microbiologists on the GMO panel did not consider relevant for their assessment that the Amflora is safe. But this is precisely the greatest concern of the detractors and their ground for claiming that GM crops are not safe. Certainly no scientist, or scientific panel, can take into account every concern that may be relevant for the final policy decision, yet the decision-making

\footnotetext{
${ }^{66}$ The reader should be reminded that local 'system of public reason' is not limited to the respective national academia (which may very well be completely 'international'), but includes many other institutions and practices which are employed to generate policy relevant knowledge. For example in Britain, "much attention is paid to the individual expert's ability to incorporate public virtues that render the expert's judgement credible," Jasanoff, 'Epistemic Subsidiarity', (n 22) 141.

${ }^{67}$ EFSA, 'Statement of EFSA on the consolidated presentation of opinions on the use of antibiotic resistance genes as marker genes in genetically modified plants' The EFSA Journal 1108 Appendix D, emphasis added.
} 
system as a whole ought to be able to take into account such concerns too, including when it is a very high level one, such as the EU or WTO. Thus in my view, the upper level can pre-empt the authority of the local one, not on the account of the superiority of its knowledge, but on the account of its greater social robustness. ${ }^{68}$ This is a tall order, but in any event the ability of transnational regulation to assert authority must be able to recognize locally salient knowledge, and integrate it in the justificatory discourse, rather than ignore, or explain it away as it often does. The Impact Assessment process of the EU, albeit still exhibiting major shortcomings, is one good example how different and incommensurable claims can be accounted for. Making the assumptions of the risk assessment explicit (1) and contestable (2) is the bare minimum. meet.

Thus, achieving social robustness of knowledge is the first strategy to accommodate the collision, which is reliant on a significant degree of cooperation between the different levels. The second strategy is to take the competition between the two levels for what it is worth. Instead of waiting for the contradictions to arise, and try to resolve them by inclusion of the considerations emerging at the lower level, the higher level epistemic system may try to produce authoritative knowledge before the issue has come into the focus at the level below. The EU, as well as many other transnational regulators, are often able to frame the issue, and define what is relevant and what not before anyone else could even think of the problem. ${ }^{69}$ As already noted, when debates in national public spheres reach certain fairly stable conclusion, it becomes very difficult to challenge, because deliberative publics tend to polarize. In theory, this should be possible for supranational publics like the EU, provided that there is such public at Paneuropean level and that it does engage in deliberation. If, and this is a big if, this happens, the

\footnotetext{
${ }^{68}$ The term I borrow from Helga Nowotny, 'Democratising Expertise and Socially Robust Knowledge' (2003) 30 Science and Public Policy 151-156.

${ }^{69}$ The EU regulation of nanotechnologies is a successive example of such preemptive strategy, see Tanja Ehnert, 'The Legitimacy of New Risk Governance-A Critical View in Light of the EU's Approach to Nanotechnologies in Food' (2015) 21 European Law Journal 44-67.
} 
Paneuropean knowledge may become authoritative and its claim on validity may preempt any local considerations. Note that the competitive strategy also involves a degree of cooperation, but this time it is not dialogue between the various levels but deliberation between agents at the same level—scientists, lobbyists and civil society organisations in Brussels, Geneva or New York as the case may be. To the extent that the stakeholders are authoritative themselves, they shall be able to negotiate authoritative settlement too. Indeed, in many cases this seems to be what is happening in Brussels and the authority of many assessments goes unchallenged in any Member State. ${ }^{70}$ In some cases however and genetic engineering is the case in point - there are debates on both Paneuropean level and national (although the latter may be happening in some Member States only). Then the competition becomes visible, and any public, which has already formed certain opinion, or which has brought forward certain considerations as important, is unlikely to recognise any claims on the contrary. In this competition each level has certain comparative advantages. On one hand, the national public spheres are by far more robust and the national systems for production of knowledge more developed and more trusted. They are better equipped to identify individual problems, and turn them into matters of public concern. On the other hand, EU usually has better institutional capacity to deal with matters so specialised (and in any event more resources than many of the member states). The other thing which gives it competitive edge, is that specialised issues enjoy much less attention in the generalist national public spheres, while remain of high concern for specialised publics which are already present in Brussels. The Union institutions seem to have grasped this and try hard to be ahead of the member states in opinion formation. It has very few chances on matters, which have always been of high

\footnotetext{
${ }^{70}$ One problem with this is the question who ought to participate and whose views are to be accounted for in transnational governance. For all the studies of civic participation in various contexts, a developed theory for inclusion and participation is still missing. A remarkable step towards one is made by John S. Dryzek and Simon Niemeyer, 'Discursive Representation' (2008) 102 American Political Science Review 481.
} 
national concern - foreign policy, taxation or immigration - there the Paneuropean reason is bound to lag behind. A good example for European public opinion - against an EU proposal-may have been the protests against the Anti-Counterfeiting Trade Agreement (ACTA), where no national positions loomed large. Another, less salient case might be the public support for the moratorium on the neonicotinoids - all Europeans seems to have woken up as bee-lovers and with few voices against even though the ban may have been very costly for certain farming states. Now, the first strategy described above is mostly normative. Epistemic subsidiarity in a multilevel regulatory system requires socially robust knowledge, but it rarely happens in the EU. It is even rarer in the other transnational regulators, but as the discussion of the FSC in this symposium shows, sometimes they have done a better job in integration of various concerns and trustbuilding. ${ }^{71}$ On the other hand, the second strategy in my view describes what actually happens - the claims for authoritative answer to regulatory issues on various levels compete, and usually the lowest level wins the minds (and hearts) of citizens. When the legal instruments of the upper level have supremacy in the face of the authority build at the lower, deficits occur. As a matter of subsidiarity (not only epistemic) and also as a matter of prudency, such cases should be avoided. This brings us to the third strategy that is pragmatic. It suggests that assessments are to be left to the level where the highest institutional capacity for public reasoning in certain area is available. ${ }^{72}$ In this context institutional capacity should be understood both in terms of expertise (i), and in terms of capacity for accounting for the local concerns (ii) which are relevant for different societies or parts thereof. Wherever expertise-cum-inclusion is, there the locus of decision-making should be. The capacity for inclusion already surfaced in the discussion

\footnotetext{
${ }^{71}$ See in this volume Jaye Ellis.

${ }^{72}$ If not readily obvious, this is prompted by the Comparative Institutional Analysis developed by Neil Komesar, see Neil K Komesar, Imperfect Alternatives: Choosing Institutions in Law, Economics, and Public Policy (University of Chicago Press 1994).
} 
of the competitive advantages at each level. Although by itself the capacity for robust deliberation and for production of rigorous policy relevant knowledge does not guarantee that the actual settlements reached will gain acceptance by the relevant public(s), it might be the best proxy which we have.

It should be clear that for all the talk about the respect for local epistemic practices, this paper does not recommend that the lower decision-making is to be preferred. Indeed, each of the three strategies just outlined can point at different level, depending on the issue and the circumstances. Unlike subsidiarity principle of the EU, which makes the lower level the default, epistemic subsidiarity imposes a requirement on the higher level, to try to accommodate the concerns formulated at the lower. Further, the requirement for respect operates also horizontally - to all stages of decision-making, 'scientific' as well as 'political'. Even the most technical decisions - such as collecting raw data for a particular GMO variety - should be at least in principle open to questions and the terms of reference experts receive may differ. ${ }^{73}$ It is not a matter of finding the stage that is 'really technical only', it is about finding a way for science and politics to feed into each other at each level. Thus, epistemic subsidiarity suggests a radical alternative to the current approach which is to circumscribe the 'appropriate' domains where each of the two is sovereign. It is not a call to move the borders, but to find ways for communication across them.

Respecting epistemic subsidiarity is obviously a tall order but there seem to be a precious few examples of transnational authorities which fare better than EFSA on this count. In her paper in this symposium Jaye Ellis is quite critical of the FSC and Marine Stewardship Council (MSC), however the glass might be half full. Unlike the European GMO regime, which was endowed formal powers so the institutions could afford to remain complacent, both councils had to struggle to build their authority and they did by

\footnotetext{
${ }^{73}$ Ellis, ibid.
} 
being more inclusive and more respectful. The internal development of certain 'functional equivalents' of the features of the constitutional state, including 'an echo of an oppositions' which facilitates wider participation and contestation have been helpful too. $^{74}$ Oren Perez gives another wonderful example of an institution that was fairly successful in building its own authority by inclusion of quite diverse local knowledge the International Panel for Climate Change (IPCC). It has developed a unique framework which allows it to take into account a wide variety of knowledge, including both the one produced by radical ecologists and that of climate change deniers. ${ }^{75}$ Certainly, the world is still far from finding an adequate response to the climate change, and quite a few American senators continue to deny its very existence, but it is remarkable that all governments around the world generally accept the claims of the IPCC; acting on them is quite a different issue. $^{76}$

A final distinction that needs to be made is with constitutional pluralism. ${ }^{77}$ Epistemic subsidiarity is also pluralist in the sense that it rejects the hierarchical system of authority, in science in its case. But it is different concept and at least in principle it can live well even within a monist system of political authority. Indeed, although the EU itself is considered to be a pluralist system, the system for GMO regulation described in section two is fully hierarchical. In that sense epistemic subsidiarity may stand closer to pluralism under the constitution rather than pluralism of constitutional orders.

\footnotetext{
${ }^{74}$ Ellis, ibid, also points that the choice between different methodologies for measurement are in fact choices between different types of blind spots.

${ }^{75}$ See Perez, 'The Hybrid Legal-Scientific Dynamic of Transnational Scientific Institutions' (n 65). As Perez notes, this may be tantamount to including the predictions of a group of astrologists in the conclusions of the International Astronomical Union.

${ }^{76}$ It is well beyond the scope of this paper to attempt to solve this problem, but the principle of epistemic subsidiarity requires that the evangelicals who refuse to accept the IPCC's claims because it contradicts to their epistemic horizons, they should not be silenced or ignored. Respecting their established epistemic practice - reading the Bible - the IPCC may appoint a minister, who can argue on their terms, perhaps finding a line, which warns about looming global disaster. As ridiculous to my own atheist mind this is, and as wasteful for a scientist may be, Pope Francis seem to have grasped the need to contribute along this lines.

${ }^{77}$ See for example Nico Krisch, Beyond Constitutionalism: The Pluralist Structure of Postnational Law (Oxford University Press 2010).
} 
Constitutional pluralism describes the latter - a situation where different legal orders make competing claims for prevalence over each other - an accurate description of the contemporary world in my view - and tends to celebrate it. Epistemic subsidiarity is also descriptive in the sense that it exposes the context-dependency of knowledge and the related failures of scientism. But it is also critical, and highly normative in the sense that it calls for respect to local epistemic practices which are usually ignored, and with that regard I have made a number of prescriptions how to deal with epistemic conflicts in a multilevel system. Yet, it potentially allows for pluralism within the hierarchical order, the way constitutionalism allows for political pluralism in the nation states.

Epistemic subsidiarity as I understand it does not answer the question about the appropriate level of decision-making directly and in any event this paper was focused on the question how to justify authority wherever it is, and not where it should be. Yet it should be obvious that in most cases it will be easier to justify an act of authority in a smaller and less diverse group. The requirement for social robustness of justification will be much more difficult to meet on a higher level and often even the best efforts will fail. Still, many other reasons may make the overarching regulation indispensable ${ }^{78}-$ the global commons are a case in point - and in such cases epistemic subsidiarity kicks in with full force, calling upon the higher-level authority to take into account the lower-level concerns nevertheless.

\section{CONCLUSION}

In this article, I have shown how a centralised regulatory order failed, and I claim that this is because of the insulation of the 'scientific' from 'other' factors. If they were integrated instead, as epistemic subsidiarity calls for, the regime could gain more

\footnotetext{
${ }^{78}$ In the EU the appropriate level of decision making is decided by the principle of subsidiarity enshrined by Art. 5 TEU, but it should not be confused with epistemic subsidiarity. The way the former is currently applied by the institutions makes it quite toothless, but this does not need to be so.
} 
confidence from the respective constituencies on one hand, and yield decisions which are narrowly tailored to accommodate their concerns. At the time of writing, the Member States are flocking to opt out of it by banning GMO cultivation on their territories, which brings the EU back at the starting position. Although the comparison may be unfair, it is telling that the number of undertakings which opt into the FSC and MSC certification is growing.

In my view, the history of the GMO regime in Europe illustrates the more general claim that has been made in the literature (STS or not) - that overwhelming reliance on science is not a way to reduce political controversy and build confidence in a transnational regulatory regime. The problem is not too much science (nor too bad science) but the way science has been employed. I have argued that instead of trying to define the domains of science and politics respectively, we should integrate them and use science to inform decision-making at every level and every stage. It also aims to reverse the common assumption that underpins the linear RA-RM model that science can be a source of trust. On the contrary - science itself needs to draw on something that is trusted. This difference may not be obvious in the established national public spheres, but comes to the fore in transnational settings. When trusted epistemic methods and procedures are ignored by purportedly universal science, the trust in 'science' itself is undermined. 